\title{
Review Article New Generation Surgical Sutures
}

\author{
N Gokarneshan* \\ Professor and Head Park College of Engineering and Technology, India
}

Submission: June 05, 2018; Published: June 15, 2018

*Corresponding author: N Gokarneshan, Professor Department of textile Technology, Coimbatore, India, Email: advaitcbe@rediffmail.com

\begin{abstract}
The article highlights some significant trends in newer types of surgical sutures. Drug delivery using suitable polymeric devices has gathered momentum in the recent years due to their remarkable properties. The versatility of polymeric materials makes them reliable candidates for site targeted drug release.. Surgical sutures are used to facilitate closure and healing of surgical- or trauma-induced wounds by upholding tissues together to facilitate healing process. There is a wide range of suture materials for medical purpose and the main types include absorbable and non absorbable.
\end{abstract}

Keywords: Sutures; Anti microbial; Drug delivery; Barbed; Smart; Biodegradable; Scaffolds

\section{Introduction}

Polymeric materials have dramatically influenced our day to day life. They find potential in various fields like food packaging, automobiles, water purification etc. [1-3]. Application of polymeric biomaterials in medicine has been a thrust area of research owing to the exceptional and superior properties they exhibit [4]. The increased use of polymeric biomaterials in the form of surgical implants, sutures and scaffolds for biomedical applications can be attributed to the exceptional versatility that they offer when compared to metal or ceramic materials [5]. Several drug delivery systems have been formulated such as controlled, slow and targeted delivery systems [6]. While conventional drug delivery systems lack specificity, polymer drug delivery carriers offer tremendous control over the drug delivery process and can be tailored to meet specific needs [7].

It is well recognised that sutures have been an effective and critical part of surgeries and trauma management [8]. The primary purpose of sutures is to hold apposing tissues together to facilitate and hasten healing process with minimal or no scar formation following an injury or surgical procedure [9]. A variety of materials such as gold, silver, iron and steel wires, dried animal gut, animal hair (e.g., horse hair), silk, tree bark, and plant fibers (e.g., linen, cotton) were used as suture materials in the past, while some of them are still in use today. The recent past has witnessed the use of various synthetic biomaterials such as polydioxanone, poly (lactic-co-glycolic acid) as suture materials [10]. However, despite the availability of a wide range of suture materials, there is no single suture material that would be suitable for all types of surgical and medical requirements [11].

\section{Sutures for simultaneous wound healing and drug delivery}

Polymers are conjugated with bioactive agents to achieve control over release kinetics and also to improve the targeting efficiency [12]. Polymeric materials can be fabricated with different functionalities and wide range of properties which make them desirable candidates for medical applications [13]. They can be engineered such that they act as site specific drug delivery systems and can also be fine-tuned to form stable biodegradable systems. Polymer sutures are described as strands of materials, synthetic or natural, intended for closure of wounds [14]. Suture threads, have a prominent role among all other wound closure devices representing a market estimated to be currently around 1.3 billion annually [15]. Acharya Sushruta considered as a pioneer of ancient Indian surgery has described various surgical procedures including suturing techniques [16]. He suggested the use of horsehair, cotton and leather for wound closure [17]. History says that some cultures witnessed the use of ants and beetles as wound closure agents. Egyptians used linen sutures along with natural adhesives to achieve proper healing [18]. Later on sutures made of silk and catgut was widely employed. Hippocrates the Father of Medicine developed plant based sutures. It is also reported that he used gold wires for sutures [19]. Joseph Lister introduced the suture material, chromic catgut in 1881. He used carbolic acid for sterilizing sutures [20]. Sutures made of silk suffered from drawbacks such as poor tensile strength and undesirable tissue reaction [21]. Natural sutures were replaced by synthetic sutures. Early 1970 s witnessed the development of sutures based on poly glycolic 
acid (PGA) followed by poly (lactic-co-glycolic acid) (PLGA) sutures $[22,23]$. Recently there has been a dramatic rise in the development of self-healing sutures that release drugs that enhance the healing process, without compromising the quality of suture. Sutures have been modified to improve tissue integrity, healing, and immune response [24]. Incorporating drugs in sutures becomes important when suturing is applied to internal organs or tissues where direct drug delivery is quite difficult [25]. The delivery of anesthetics, analgesics, anti-inflammatory agents or antibiotics from the suture directly into the wound site provides a direct and efficient route for drug delivery [26]. In this regard, drug delivery suture also known as drug eluting suture has been developed by incorporating the active pharmaceutical ingredient (API) to the suture [27]. The rationale behind using sutures for drug delivery is that controlled release systems create high local drug concentrations without excessive systemic levels. Sutures are utilized in almost all surgical procedures and hence delivering drugs using sutures eliminates the need for a foreign material to be placed in the wound bed, which might interfere with the healing process and or cause infection [28]. It is noticeable that there has been stupendous progress in the development of sutures with improved materials but not much work has been done to improve the therapeutic value of sutures. The development of sutures with additional properties like release of antibiotics or other therapeutic agents to enhance wound healing has become an attractive research area of the medical fraternity. This review portrays different types of suture materials and their fabrication, emphasizing on their role as drug delivery vehicle. Different properties of suture materials are listed in Table 1.

The role of polymers in the fabrication of biocompatible and reliable drug delivery devices with good mechanical properties is of paramount importance. The ease of engineering polymers with desired biological or chemical functionalities makes them appropriate and much preferred for biomedical applications [29]. The potential of delivering therapeutic agents or drugs using polymeric sutures have been explored recently. Recent research has focused on developing sutures with improved functionalities without compromising the quality of suture materials. Sutures still have a prominent role in hospital acquired infections. Bacteria like Escherichia coli, Staphylococcus aureus, and enterococci etc. that are common in wound site find sutures as a niche and form microbial biofilms. This can sometimes lead to chronic infections which might need prolonged treatment. In order to tackle the aforemen-tioned difficulties, researchers have come up with antibacterial sutures coated with antibiotics or other antimicrobial drugs. Recently sutures have been proposed as an excellent system for carrying bio moieties like proteins, stem cells etc. to the diseased site. The physical and chemical properties of the polymeric material are major factors that govern suture quality. For achieving a controlled and systematic delivery, the sutures should be designed such that it retains its mechanical integrity as long as is required to ensure complete wound healing. Biofilm formation on the suture surface plays a major role in surgical site infections. Braided sutures have higher tensile strength than monofilament sutures. However they facilitate bacterial adherence which adversely affect the wound healing process. Hence antimicrobial sutures have been proposed as an effective strategy than can prevent the adherence of microbes. Recently, triclosan coated sutures have been widely used in this regard. But the growing resistance to triclosan demands the need for alternatives that can enhance the antimicrobial property without adversely affecting the mechanical as well as release properties of the suture. Nanoparticles have shown much promise as an alternative to antibiotics. Sutures coated with silver nanoparticles have shown good antibacterial activity without much alteration in the tensile strength. We still have a long way to go to fabricate high quality sutures with engineered surfaces having multifunctional charac-teristics including good mechanical properties and biodegradabil-ity. Further studies are very much required to correlate the morphology, structure, and properties of the suture materials with the drug binding capability and release profile.

\section{Newer Suture Materials}

Regardless of the advancements and innovations in materials technology and surgical techniques, wound closures following surgical procedures or trauma by and large still involves the use of sutures. Some suture materials which have been available for decades are still being used routinely [30]. There is a substantial growth in the surgical sutures segment of the health care industry, with a market share of up to $\$ 649$ million for absorbable and non absorbable suture products [31]. However, a recent global forecast reveals slower growth for the sutures market due to lack of novel products in wound care. Demands for sutures materials are on the rise due to an increase in number of surgical procedures performed worldwide, regardless of the availability of sutures substitute such as surgical staples, glues, and strips in the market. These products do on occasions fall short of the stability and flexibility rendered by sutures in wound management [32]. The choice of a suture material in wound management largely depend on factors such as the number of tissue layers involved in wound closure, tension across the wound depth of suture placement, presence of oedema, expected time of suture removal, possess adequate strength, and elicit minimal or no inflammatory reactions [33]. Sutures must also possess significant pliability and flexibility for better handling characteristics during suturing. In addition, ease in knot placement, high knot security, free from irritating, or infectious substances are also highly sought after features [34]. Suture materials available for routine use fulfil most of the primary requirements, but not all. Hence, current efforts are centred on developing suture materials which has all the desired features along with the additional capabilities such as the potential to deliver drugs and cells to facilitate and/or augment 
wound healing. Newer suture materials and design have expanded the range of biomedical applications of sutures. The recent advancements and emerging trends in suture technology have immense potential in clinical/surgical applications involving specialized procedures and wound management.

This article intends to provide an overview of currently available sutures, the characteristic features, and properties of suture materials with emphasis on emerging trends such as sutures with bioactive molecules (drugs, antimicrobials, and stem cells) and smart sutures [34]. A comprehensive literature search for studies or reports on different types of sutures published until the end of September 2015 using electronic databases such as PubMed, Scopus and www.clinicaltrials. gov was performed. The search terms used in these databases include "sutures," "suture materials," "antimicrobial sutures," "antibacterial sutures," "surgical site infection", "drug eluting sutures," "stem cells sutures," "bioactive sutures," "barbed sutures," "bioactive barbed sutures," and "elastic sutures".

These terms were either used alone or in different combinations. Searched articles were limited to those published in English only. The articles were then compiled and studied for their relevance along with supportive evidence. In addition, relevant articles that were cited in the reference lists of the retrieved and chosen articles were also included. Any study or report with lack evidence supporting the findings stated in the publications was excluded from the review.

Surgical sutures play a vital role as a medical device in wound management and recent advancements have expanded its applicability and efficacy. Major progress in this front can be attributed toward the technological advancements in materials science. Polymers hold a significant potential with their high flexibility giving rise to diverse suture materials with excellent physical and mechanical properties. In addition, biodegradable polymers that can be easily broken down and excreted or resorbed without removal or surgical reconsideration have proven to be beneficial. These materials are also well known for ability as carriers for drugs, stem cells, proteins, peptides, antibodies, DNA, nanoparticles, and so forth, to the desired site thereby enhancing the therapeutic potential of sutures. The principle function and efficacy of sutures depends on the physico-mechanical properties and it is vital to retain these characteristics while they are modified or coated with bioactive agents and sensors. In addition, to better handling qualities and desired modifications, it should also be non carcinogenic, nontoxic, free of allergens, and importantly it should not evoke any adverse response in the host tissues. To meet these requirements, it is necessary to conduct detailed pre-clinical studies and evaluate the safety and efficacy in human trials on these emerging sutures. The next generation of suture materials, an outcome of multidisciplinary efforts has immense potential to impact surgical outcomes and wound management.

\section{Conclusion}

Among the various polymeric materials available biodegradable sutures has received considerable attention because they offer great promises in the realm of drug delivery. Sutures have been found to be an effective strategy for the delivery of antibacterial agents or anti-inflammatory drugs to the surgical site. Recent developments yielded sutures with improved mechanical properties, but designing sutures with all the desirable properties is still under investigation. Efforts have been made to analyze the recent developments pertaining to biologically active sutures emphasizing their potential as drug delivery vehicle. Recently, there is a growth in the development of classes of suture materials based on their properties and capabilities to improve tissue approximation and wound closure. The current and emerging trends in suture technology including knotless barbed sutures, antimicrobial sutures, bioactive sutures such as drug-eluting and stem cells seeded sutures, and smart sutures including elastic, and electronic sutures have been discussed. These newer strategies expand the versatility of sutures from being used as just a physical entity approximating opposing tissues to a more biologically active component enabling delivery of drugs and cells to the desired site with immense application potential in both therapeutics and diagnostics.

\section{References}

1. Baldino L, Cardea S, Reverchon E (2017) Biodegradable membranes loaded with curcumin to be used as engineered independent devices in active packaging. J. Taiwan Inst. Chem. Eng 71: 518-526.

2. Soyekwo F, Zhang Q, Gao R, Qu Y, Lin C, et al. (2017) Cellulose nanofiber intermediary to fabricate highly-permeable ultrathin nanofiltration membranes for fast water purification. J Membr Sci 524: 174-185.

3. Evangelisti S, Tagliaferri C, Brett DJ, Lettieri P (2017) Life cycle assessment of a polymer electrolyte membrane fuel cell system for passenger vehicles. J. Clean. Prod 142(4): 4339-4355.

4. Teo AJ, Mishra A, Park I, Kim YJ, Park WT, Yoon YJ (2016) Polymeric biomaterials for medical implants and devices. ACS Biomater. Sci. Eng 2(4): 454-472.

5. Wong JY, Bronzino JD, Peterson DR (2012) Biomaterials: Principles and Practices. CRC Press.

6. Tiwari G, Tiwari R, Sriwastawa B, Bhati L, Pandey S (2012) Drug delivery systems: an updated review. Int. J. Pharmaceut. Invest 2(1): 2-11.

7. Rissanen M, Puolakka A, Ahola N, Tonry A, Rochev Y (2010) Effect of protein-loading on properties of wet-spun poly (L,D-lactide) multifilament fibers. J. Appl. Polym. Sci 116(4): 2174-2180.

8. Ethicon Inc(2005) Wound Closure Manual

9. Mackenzie D (1973) The history of sutures. Med Hist 17(2):158-168.

10. Greenberg JA, Clark RM (2009) Advances in suture material for obstetric and gynecologic surgery. Rev Obstet Gynecol 2(3): 146-158.

11. Greenberg JA (2010) The use of barbed sutures in obstetrics and gynecology. Rev Obstet Gynecol 3(3): 82-91.

12. Liechty WB, Kryscio DR, Slaughter BV, Peppas NA (2010) Polymers for drug delivery systems. Annu Rev Chem Biomol Eng 1: 149-173. 
13. Kulshreshta AS, Mahapatro A (2008) Polymers for biomedical applications. American chemical society 1: 1-7.

14. Dumitriu S (2001) Polymeric biomaterials, Revised and expanded ( $2^{\text {nd }}$ edn.), CRC press, USA.

15. Champeau M, Thomassin JM, Tassaing T, Jerome C (2017) Current manufacturing processes of drug-eluting sutures. Expert opinion drug delivery 14(11): 1293-1303.

16. Kansupada KB, Sassini JW (1997) Susrutha: the father of indian surgery and ophthalmology. Doc ophthalmol 93(1-2): 159-167.

17. Santoni Rugiu P, Skyes PJ (2007) Healing of wounds and the development of surgery. A history of plastic surgery pp. 39-78.

18. Ratner BD, Hoffman AS, Schoen FJ, Lemons JE (2004) Biomaterials science: An introduction to materials in medicine. Academic press, USA.

19. Lee May I, Lappi VG, White WG (1975) Materials for biomedical applications. Polymer engineering science 15(11): 789.

20. Muffly TM, Tizzano AP, Walters MD (2011) The history and evolution of sutures in pelvic surgery. Journal of Royal Society of Medicine 104(3): 107-112.

21. Tajirian AL, Goldberg DJ (2010) A review of sutures and other skin closure materials. Journal of Cosmetic Laser Therapy 12(6): 296-302.

22. Kaplan JA, Lei H, Liu R, Padera R, Colson YL et.al (2014) Imparting super hydrophobicity to biodegradable poly (lactide-co-glycolide, electrospun meshes. Biomacromolecules 15(7): 2548-2554.

23. Gallo AL, Paladini F, Romano A, Verri T, Quattrini (2016) Efficacy of silver coated surgical sutures on bacterial contamination, cellular response and wound healing. Material science and Engineering $\mathrm{C}$ Mater Biol Appl 69: 884-893.
24. Wang L, Chen D, Sun J (2009) Layer by layer deposition of polymeric microgel films on surgical sutures for loading and release of ibuprofen. Langmuir 25(14): 7990-7994.

25. Kiran Shankar H (2016) A comparative study of outcome of the absorbable suture polyidxinone and non absorbable suture polypropylene in laparotomy wound closure. International journal 4(6): 2084-2088.

26. Padmakumar S, Joseph J, Neppallli MH, Mathew SE, Nair SV (2016) Electrospun polymeric core sheath yarns as drug eluting sutures. ACS Applied material interface 8(11): 6925-6934.

27. Dennis C, Sethu S, Nayak S, Mohan L, Morsi YY, et.al (2016) Suture materials-current and emerging trends. Journal of Biomedical material research Part A 104(6): 1544-1559.

28. Weldon CB, Tsui JH, Shankarappa SA, Nguyen VT, Ma M, et.al (2012) Electrospun drug eluting sutures for local anaesthesia. Journal of control reliability 161(3): 903-909.

29. Blessy J, Anne G, Sreeraj G, Nandakumar K, Thomas S (2017) Polymer sutures for simultaneous wound healing and drug delivery - A review. International journal of pharmaceutics, 524(1-2): 454-466.

30. Global Sutures Market Research Report (2015).

31. (2013) Demand for surgical sutures high: Rise in surgical procedures performed globally.

32. Edlich RF (2008) Surgical Knot tying manual ( $3^{\text {rd }}$ edn.).

33. Hochberg J, Meyer KM, Marion MD (2009) Suture choice and other methods of skin closure. Surg Clin North Am 89(3): 627-641.

34. Ratner BD, Hoffman AS, Schoen FJ, Lemons JE (1996) Biomaterials science: An introduction to materialsinmedicine. Applications of Materials in Medicine and Dentistry. Academic Press, USA pp. 356-359.

\section{Your next submission with Juniper Publishers} will reach you the below assets

- Quality Editorial service

- Swift Peer Review

- Reprints availability

- E-prints Service

- Manuscript Podcast for convenient understanding

- Global attainment for your research

- Manuscript accessibility in different formats

( Pdf, E-pub, Full Text, Audio)

- Unceasing customer service

Track the below URL for one-step submission https://juniperpublishers.com/online-submission.php 